diferentes atrocidades humanas. La literatura de Rosero es una voz poética para la paz, porque es imposible evadirse de una "intuición imaginativa", de "escribir contra viento y marea", cuando "nunca ocurre lo que yo premedito; eso es lo mágico de escribir. Sin fórmulas", frases que sostiene en su entrevista.

Los editores agradecen a los ensayistas que se reúnen para evadir el silencio de la crítica literaria en Colombia, dignos de elogiarse por su calidad y el tono riguroso de la mayoría de los textos; agradece Rosero la entrevista, y a los lectores; agradezco yo también el privilegio de reseñarlo, pues es un autor que no me era tan cercano como lo siento ahora. Entre la controversia y el vértigo, me propongo compartir este autor con mi hija (quien ha leído cuentos infantiles de Clarice Lispector); ahora podemos leer juntas el Aprendiz de Mago y otros cuentos de miedo (1996), para atravesar los ciclos de la creación literaria, en una íntima conexión con la narrativa de Evelio Rosero.

Elsa Leticia García Argüelles

Universidad Autónoma de Zacatecas

\title{
Brigitte Adriaensen y Marco Kunz (Eds.). Narcoficciones en México y Colombia. Madrid/Frankfurt: Iberoamericana/Vervuert, 2016, 258 páginas
}

La representación del narco y sus redes tentaculares han invadido no solo los productos masivos de la cultura, sino también ha permeado la narrativa latinoamericana para quedarse. Ya no puede ser considerado un epifenómeno como tampoco una tendencia que marca una literatura de corte popular y de ratings audiovisuales; es ya objeto de investigaciones académicas como el libro que reseñaremos a continuación. En la "Introducción" (9-24), firmada por Brigitte Adriaensen, se comienza apuntando esa extrañeza y malestar de que el narcotráfico irrumpe, con sus tentáculos de poder y de violencia, en los imaginarios culturales; se trata de un tragedia de orden social o de la justicia ligada al flujo y a redes internacionales, más allá del reduccionismo estereotipador de que sea un problema endémico de Latinoamérica. Ahora bien, Adriaensen plantea el término de "narcoficciones", para designar aquellos productos culturales, cine, música, telenovelas, teleseries o literatura que "versan sobre el narcotráfico" (11). Su impacto cultural y mediático se observa desde los narcorridos mexicanos de los Tigres del Norte o Los Tucanes de Tijuana, hasta las teleseries como El cartel de los sapos (2008, Caracol Televisión) a Pablo Escobar, el patrón del mal (2012, Caracol Televisión), en donde se reivindica la figura del "narcotraficante" (12). Estas producciones seriales se cuestionan porque no ofrecen una perspectiva más antropológica o de crítica incisiva a ese "espectáculo de la violencia" (13). Este balance inicial, Adriaensen lo complementa con el cine, en donde películas como la colombiana María, llena eres de gracia (2004) o la mexicana Miss Bala (2011) abordan la cuestión humana del narcotráfico y la inmigración; pero no superan los circuitos de festivales, mientras la "narconovela" apenas se vende, en detrimento de los reportajes periodísticos y crónicas como la de Carlos Castaño, Mi confesión (2001), la cual vendió más de 110000 ejemplares (15).

Estereotipos abundan, como aquel relacionado con la preeminencia de la narcoliteratura en el regionalismo norteño mexicano, o con la "representación estereotipada y a veces banalizada de la violencia" (15), a lo que hay que agregar también una "despolitización" o una "fetichización de la figura del narco". Ante este panorama se impone un discurso más analítico que estudie las relaciones centro-periferia en el caso mexicano, o la experiencia de 
la violencia, más allá de la ostentación, el sentimentalismo o lo melodramático. Eso es lo que han realizado los participantes de este volumen. En el primer artículo, Margarita Jácome se interesa por la recepción de este tipo de novelas y la percepción del narcotráfico en Colombia; su “¿Narco-novela o novela del narcotráfico? Apuntes sobre el caso colombiano" (27-52) precisa ese malestar e incomodidad tanto de la crítica como de la opinión pública para aceptar y reconocer a un escritor como Hernán Hoyos, quien desde Coca: novela de la mafia criolla (1977) abordaba esta temática y fue relegada a las ventas del quiosco de revistas. Pero a a partir de los 80 del siglo pasado, estas novelas llegaron para quedarse de la mano de Juan Gossaín y Gustavo Álvarez Gardeazábal. Leídas como retrato muy poco cambiado de la realidad, el éxito de La bestia desatada (2007), de Guillermo Cardona, merece la atención con el auge de las teleseries de principios del XX, en donde la violencia desatada por Pablo Escobar muestra las tretas y las mañas del sicariato dentro de una "vorágine". Otro panorama general para el caso mexicano lo ofrece Marco Kunz en "Vuelta al narco mexicano en ochenta ficciones" (53-79), quien además de ofrecer un catálogo de narrativa de ficción y no ficción, hace un listado de películas sobre esta temática. Abordar este fenómeno implica tomar en cuenta también la extorsión, el secuestro, la impunidad y la corrupción; pero estos grupos mafiosos o delicuenciales operan de una manera en que sus redes y actos en general deben someterse al sigilo y a la clandestinidad. Por esa razón, toda representación del narco "es siempre parcial y borros[a]" (54) y, ante esa invisibilidad, la literatura y el cine crean. Para Kunz, no hay una "narconovela", porque sus formas son muy disímiles y prefiere hablar de una narrativa que trata "el narcotráfico y los problemas que genera" (58), a partir de Diario de un narcotraficante (1967), de Ángelo Nacaveva, aunque las primeras de éxito editorial son El cadáver errante (1993), de Gonzalo Martré, y La vida de un muerto (1998), de Óscar de la Borbolla. Kunz pone atención a la hibridez genérica del nuevo milenio en donde la forma del relato de detectives y novela gótica alían las investigaciones sobre crímenes sin resolver o en ambientes marginales. Por su parte, Glen Close en "Restos del narco: el impulso necropornográfico en la narconovela mexicana" (81-105) analiza la relación genérica propiamente dicha con lo "negro" y lo "necro" (81), partiendo de ese descompromiso que muestra con la novela policiaca clásica, más en concreto, con su conciencia crítica frente a los gánster y a la criminalidad organizada. Así, la profusión y el muestro de cadávares para llamar la atención desembocan en una retórica de lo abyecto, al mostrar pornográficamente la muerte en directo; esto que en cine se denomina smuff, Close lo desarrollará en ese acto de mostrar "la tortura y el asesinato de una mujer" (82), de cadáveres femeninos en una trama despiadada en Cementerio de trenes (2001), de Gonzalo Martré o de desnudos de cuerpos femeninos erotizados y violentados en Balas de plata (2008) o La prueba del ácido (2010), de Élmer Mendoza.

Continúan una serie de estudios particulares sobre algún autor y obra. Brigitte Adriaensen analiza, en "Turisteando en Narcolandia: la comodificación de la violencia en Arrecife de Juan Villoro" (109-124), el auge del "tanaturismo", la visita de lugares relacionados con la muerte, con una pretensión al voyeurismo y al morbo generado por el "capo" y los "cárteles"; la novela del mexicano Juan Villoro, Arrecife (2012), pone a unos turistas de un resort de la región maya en contacto con la guerrilla y la mafia; su búsqueda se canaliza hacia sensaciones fuertes para estar "viviendo con el peligro". En "Juegos, aguafiestas y mascaradas en Mi nombre es Casablanca" de Juan José Rodríguez (125-149), Kristine Vanden Berghe analiza esta novela del mexicano del año 2003 desde la noción del juego, la representación 
lúdica que el ser humano hace y realiza, para que la guerra sea una forma de juego, en este caso degenerado de un combate signado por la "guerra florida" de dos capos en Mazatlán. Importa destacar la presencia del detective Luis Ayala, quien narra la historia desde una perspectiva un poco borrosa y nada transparente (139). Para el caso colombiano, François Degrande se propone analizar la relación dinero-sexo-drogas en esta novela del año 2001 en "Los riesgos del juego. Efectos secundarios de la lectura en La lectora de Sergio Álvarez" (151-169). El secuestro de una estudiante universitaria, para que les lea a sus secuestradores una novela en donde están las claves para encontrar un maletín con dos millones de dólares del narco, desencadena una narración a dos niveles, cuyo segundo realiza una descripción del mundo del narcotráfico en Colombia. A la novelista mexicana Orfa Alarcón, quien publica este relato perturbante en 2010, Verónica Saunero-Ward dedica su estudio sobre "Perra brava: una historia de amor perversa" (171-184). En ella la protagonista es una joven universitaria, Fernanda Salas, quien se encuentra traumatizada desde su infancia al presenciar el asesinato de su madre por parte de su padre. El conflicto con este último y su enamoramiento por parte de un narco de Monterrey marcan una historia recapitulativa y de liberación personal en su desenlace, para que el machismo, la perversidad y el sadomasoquismo indaguen sobre la violencia y la transformación posible del sujeto femenino. Otro caso mexicano estudia Margarita Remón-Raillard en "Trabajos del reino de Yuri Herrera: la narcoliteratura en México como reflexión identitaria, crítica del presente e interrogante sobre la autonomía del arte" (185-202). El protagonista de esta historia es un cantante de corridos, Lobo, que se deja deslumbrar por el mundo de la droga y empieza a componer como "músico personal" de su mecenas. Las referencias al narcotráfico y a la frontera son escasas para que el cantante haga toda una exposición sobre el papel del artista y la autonomía del arte a manera de autojustificación de su mala conciencia; es más, llega a naturalizar la violencia y el papel de la muerte en el contexto mexicano. La novela es del 2003. En esta misma línea, Reindert Dhondt se interesa por la impronta de este género popular de la música sobre la ficción narrativa en "La narcoficción mexicana entre novela y corrido" (203-220), el cual ha impregnado fuertemente los estereotipos y mitos sobre el narco, a partir de los 70 del siglo pasado. El tono panegírico a su figura, emulado en una épica que alaba sus proezas en tanto traficante o bandido, exalta la lealtad, el honor, la virilidad en tanto valores por inmortalizar, frente a su función indirecta de apología al consumo y al tráfico de estupefacientes (203); ese es no solo el riesgo del narcorrido, sino también de novelas como Juan Justino judicial (1996), de Gerardo Cornejo, o Trabajos del reino, ya analizada.

Dos trabajos más cierran el volumen. "La preocupación por la literatura en la narcoliteratura" (223-235), de Felipe Oliver, y el de Hermann Herlinghaus, uno de los especialistas pioneros en el estudio de esta temática, con el título de "Narcocorridosnarconarrativas-narcoépicas: espacios heterogéneos de imaginación/ representación" (237253), los cuales pueden servir de cierre conclusivo. En el primero, Oliver descubre la presencia, en muchas de estas novelas, de personajes venidos del mundo de las letras, para luego analizar tres casos en particular, Trabajos del reino, ya citada, y las colombianas Cartas cruzadas (1993), de Darío Jaramillo, y La Virgen de los Sicarios (1994), de Fernando Vallejo. En el segundo, Herlinghaus nos invita a ubicar la narco-representación fuera del contexto regional, porque se trata de un problema de tentáculos globales y que no puede circunscribirse a la maniquea oposición entre Bien/Mal, o a la oposición socio-económica de Norte/Sur y, para 
ello, nos recuerda la presencia de narcóticos en la literatura a partir del siglo XVIII, ligada al comercio mundial y a la dominación geopolítica de Europa imperial (241).

Jorge Chen Sham

Universidad de Costa Rica

Miembro correspondiente Academia Nicaragüense de la Lengua

Miembro correspondiente Academia Norteamericana de la Lengua Española

\section{Lope de Vega. Las bodas entre el Alma y el Amor Divino. El hijo pródigo. Edición de J. Enrique Duarte. Kassel: Reichenberger, 2017, 282 páginas}

La edición de los "Autos sacramentales" de Lope de Vega tiene en este primer volumen un loable e ingente esfuerzo que termina por justificar la necesidad de publicar este corpus de piezas menores dramáticas con "suficiente anotación que proporcione al lector moderno los instrumentos textuales para entender su riqueza" (13). Se trata del primer volumen que firma y edita J. Enrique Duarte y que contempla, para este caso, la edición crítica de los siguientes autos sacramentales, Las bodas entre el Alma y el Amor Divino y El hijo pródigo, los cuales aparecen insertados en El peregrino en su patria (1604) de Lope de Vega.

La edición ofrecida por Duarte es impecable, profusa en notas y en detalles explicativos para comprender la red de alusiones históricas, idiomáticas y culturales sobre las que se sostiene el entramado bíblico y teológico de estos autos, aunque a veces se apegue tanto a ese guion filológico en el que las sendas introducciones a las piezas desemboca para presentar un cierto mecanicismo (esquema métrico, síntesis argumental, crítica, variantes, ediciones modernas) del que es difícil, hay que confesarlo, sustraerse también. El apartado 7, "Estudio textual conjunto: Las bodas y El hijo pródigo" (27-40), permite comparar el texto base que ofrece Duarte para explicar las erratas y variaciones en relación con la príncipe; pero echo de menos un elemento de peso en la historia literaria y la recepción textual de estos autos sacramentales y que hubiera podido Duarte, al menos, dedicarle unos párrafos.

Como él indica son dos autos sacramentales que aparecen insertados en un texto mayor, El peregrino en su patria, respectivamente, al final del "Libro segundo", acota para Las bodas (17), mientras que para el segundo, El hijo pródigo, extrañamente no lo indica. Entonces, son piezas que, si bien es cierto pueden leerse e interpretarse independientemente y pueden por lo consiguiente adquirir una autonomía textual, deberían ubicarse primeramente en esa novela de tipo bizantino que las cobija y les da su coherencia argumentativa y estilística. Porque sendos autos tienen una función en el clímax y acentuación no solo de las emociones/ pasiones del conflicto psicológico de los personajes en la novela de Lope de Vega, sino también de la experiencia propiamente religiosa, que ambas piezas resaltan y subrayan para que vengan a ser un soporte y un intensificador de lo que se juega en el plano narrativo.

En cuanto a los textos, en Las bodas entre el Alma y el Amor Divino el ambiente de epitalamio y de ambiente pastoril dominan para que se introduzca como tal la representación teatral, que el trono y la maquinaria refuerzan: la propaganda fidei y los personajes alegóricos se instauran en ese mundo de oposiciones morales que hace de la salvación divina el centro de ese camino para que el Alma inicie su periplo hacia la divinidad, el Amor Divino, crucificado y centro de la redención posible. Se trata de una pieza catequística, en donde todo está 